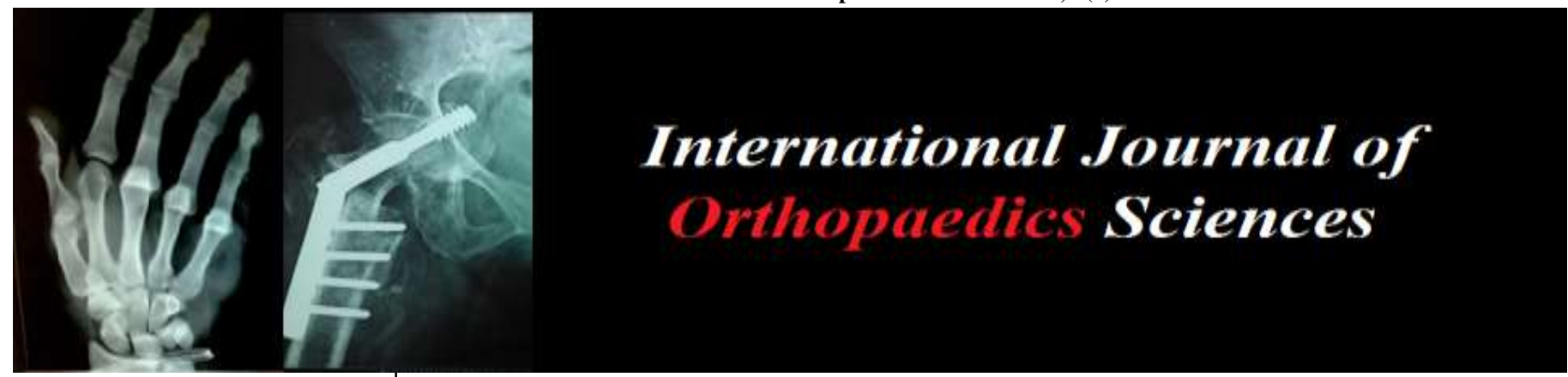

E-ISSN: 2395-1958

P-ISSN: 2706-6630

IJOS 2020; 6(4): 686-688

(C) 2020 IJOS

www.orthopaper.com

Received: 01-08-2020

Accepted: 06-09-2020

Dr. Avinash Kuma

Senior Resident, Department of

Orthopaedics, Mata Gujari

Memorial Medical College and

Lions Seva Kendra Hospital,

Kishanganj, Bihar, India

Dr. Anubhav Jain

Senior Resident, Department of

Orthopaedics, Mata Gujari

Memorial Medical College and

Lions Seva Kendra Hospital

Kishanganj, Bihar, India

Dr. Saurabh Kumar

PG Resident, Department of

Orthopaedics, Mata Gujari

Memorial Medical College and

Lions Seva Kendra Hospital,

Kishanganj, Bihar, India

Dr. Rahul Raj

PG Resident, Department of Orthopaedics, Mata Gujari

Memorial Medical College and

Lions Seva Kendra Hospital,

Kishanganj, Bihar, India
Corresponding Author: Dr. Anubhav Jain

Senior Resident, Department of Orthopaedics, Mata Gujari

Memorial Medical College and

Lions Seva Kendra Hospital,

Kishanganj, Bihar, India

\section{Study on functional outcome of non-union of tibial fractures managed by Ilizarov technique}

\author{
Dr. Avinash Kumar, Dr. Anubhav Jain, Dr. Saurabh Kumar and Dr. \\ Rahul Raj
}

DOI: https://doi.org/10.22271/ortho.2020.v6.i4j.2406

\section{Abstract}

Background: Non-united and infected fractures of tibia are challenging to orthopedicians. These cases are best managed by Ilizarov technique. The present study was done to assess outcome in these cases.

Methods: The present observational study included 19 cases of non-united fracture of tibia. Clinical details and findings of outcomes were noted.

Results: $57.9 \%$ of the cases had excellent outcome, $26.3 \%$ showed good result while poor result was seen in $5.3 \%$. Functional outcome assessment showed that $68.4 \%$ had minimal disability, $15.8 \%$ had moderate disability while $5.3 \%$ had severe disability.

Conclusion: Ilizarov technique has good outcome in non-united fractures of tibia. Pin site infection of common but can be managed adequately.

Keywords: Functional outcome, Ilizarov technique, Non-union, Tibial fracture

\section{Introduction}

Tibial fractures frequently result in non-union or malunion and is one of the challenging problems faced by an orthopaedic surgeon ${ }^{[1]}$. They are complicated by infection. $2.5 \%$ of closed tibia fractures have non-union. Poor stabilisation of fractures leads to poor contact between the fracture surfaces, bone defects or infection. Internal fixation with or without bone grafting can be done to treat these fractures. However, it cannot be done if non-union is associated with infection, bone deformity or bone exposure ${ }^{[2]}$. Ilizarov technique depends upon distraction osteogenesis by gradual stretching of bone and soft tissues. Immediate weight bearing is achievable due to stability of the fixator without compromising the soft tissue attachment and vascularity of fragments. Delayed weight bearing and difficulty in internal fixation can cause longer times to healing ${ }^{[3]}$. Ilizarov circular fixation is advocated for fracture with extensive dissection, deficiency of bone stock, and comminuted fracture ${ }^{[4]}$.

This technique partly depends upon motivation of patient and self-care. Researchers have explored the outcome of Ilizarov fixation in non-union of tibial fractures ${ }^{[5-11]}$. Very few studies have been conducted in this area and hence, this study was done.

Aims \& Objectives: The present study was conducted to assess the outcome of Ilizarov circular fixation method of treatment for the management of non-united fractures of tibia.

\section{Material and Methods}

- Study design: The present study was hospital- based observational.

- Study place: The present study was conducted at the department of Orthopaedics, Mata Gujari Memorial Medical College and Lions Seva Kendra Hospital, Kishanganj.

- Period of study: The present study was conducted between November 2017 to October 2019.

- Study population: The study population included adult patients found to be suffering from non-united fractures of tibia.

- Inclusion criteria: The patients above 18 years of age found to be suffering from nonunited fractures of tibia were included. 
- Exclusion criteria: Patients having intra-articular fracture and having injury to neurovascular bundle were excluded.

- A total of 19 patients reporting during the study period were included.

- Study tools: Pre-tested proforma was used for data collection. It included questions related to demographic profile of the study subjects, their clinical history and the details of management and outcome.

- Data collection procedure: The study subjects were recruited from the orthopaedics department of the institute. Demographic, clinical and surgical details of the patients were obtained. Thorough irrigation and debridement of wound was done for all the patients with open wound followed by fracture fixation. Prophylactic antibiotics were given. Comminuted fractures were managed by gradual distraction at the rate of $1 / 2 \mathrm{~mm} /$ day for 3 weeks followed by compression. Articular surface congruency was maintained in Juxta-articular fractures. Weight bearing was allowed as per the tolerance of the patient. Pin site infection was managed by regular dressing. Post-operative follow-up was done at every 3 weeks and radiographs were also taken until the fracture healed. All patients were advised early range of motion exercises which were started after 2 to 4 days. Outcome was assessed using bone score and lower extremity functional scale.

- Data analysis: Data entry was done using Microsoft Excel 2010 and analysis was done using Statistical Package for Social Sciences (SPSS) v 20.0. Numerical data was summarized as mean and SD while categorical data was presented as frequency and percentage. p-value $<0.05$ was considered to be statistically significant.

- Ethical consideration \& permission: Informed consent was taken from all the study subjects. Permission was obtained from Institutional Ethics Committee. Confidentiality of records was maintained.

\section{Results}

A total of 19 patients were included in the present study. It was seen that $84.2 \%$ of the cases were males. Mean age was found to be 29.3 years. Right limb was involved in 3/4th of the cases. Road traffic accident was responsible in most of the cases.

Table 1: Showing characteristics of the patients

\begin{tabular}{|c|c|c|c|}
\hline Characteristics & Values & Frequency & \% \\
\hline \multirow{2}{*}{ Sex } & Male & 16 & 84.2 \\
\cline { 2 - 4 } & Female & 3 & 15.8 \\
\hline \multicolumn{2}{|c|}{ Age (in years) } & \multicolumn{2}{|c|}{29.3} \\
\hline \multirow{2}{*}{ Side } & Right leg & 14 & 73.7 \\
\cline { 2 - 4 } & Left leg & 5 & 26.3 \\
\hline \multirow{2}{*}{ Mode of injury } & RTA & 16 & 84.2 \\
\cline { 2 - 4 } & Assault & 3 & 15.8 \\
\hline
\end{tabular}

Table- 2 shows the bone score among these cases. $57.9 \%$ of the cases had excellent outcome, $26.3 \%$ showed good result while poor result was seen in $5.3 \%$.

Table 2: Showing bone score

\begin{tabular}{|c|c|c|}
\hline Bone score & Frequency & \% \\
\hline Excellent & 11 & 57.9 \\
\hline Good & 5 & 26.3 \\
\hline Fair & 2 & 10.5 \\
\hline Poor & 1 & 5.3 \\
\hline
\end{tabular}

Table-3 shows the functional outcome. $68.4 \%$ had minimal disability, $15.8 \%$ had moderate disability while $5.3 \%$ had severe disability.

Table 3: Showing functional outcome

\begin{tabular}{|c|c|c|}
\hline Functional outcome & Frequency & \% \\
\hline Minimal disability & 13 & 68.4 \\
\hline Moderate & 3 & 15.8 \\
\hline Severe & 2 & 10.5 \\
\hline Crippled & 1 & 5.3 \\
\hline Bedbound & 0 & 0 \\
\hline
\end{tabular}

Table-4 shows the complications of management by Ilizarov technique. Pin site infection was seen in $78.9 \%$ cases, angulations in $31.6 \%$ and shortening in $10.5 \%$.

Table 4: Showing complications

\begin{tabular}{|c|c|c|}
\hline Complications & Frequency & \% \\
\hline Pin track infection & 15 & 78.9 \\
\hline Angulations & 6 & 31.6 \\
\hline Restriction of ROM & 5 & 26.3 \\
\hline Shortening & 2 & 10.5 \\
\hline
\end{tabular}

Table- 5 shows the time taken for radiological union. In $68.4 \%$ cases, union was seen within 20 weeks while $10.5 \%$ cases needed more than 30 weeks.

Table 5: Showing time taken for radiological union

\begin{tabular}{|c|c|c|}
\hline Duration (in weeks) & Frequency & \% \\
\hline $10-20$ & 13 & 68.4 \\
\hline $20-30$ & 4 & 21.1 \\
\hline $30-40$ & 2 & 10.5 \\
\hline
\end{tabular}

\section{Discussion}

The present study was conducted to assess the outcome of management of non-united cases of tibial fracture managed by Ilizarov technique. A total of 19 patients were included. It was seen that $84.2 \%$ of the cases were males. Mean age was found to be 29.3 years. Right limb was involved in 3/4th of the cases. Road traffic accident was responsible in most of the cases.

According to bone score, $57.9 \%$ of the cases had excellent outcome, $26.3 \%$ showed good result while poor result was seen in $5.3 \%$. Functional outcome assessment showed that $68.4 \%$ had minimal disability, $15.8 \%$ had moderate disability while $5.3 \%$ had severe disability. Pin site infection was seen in $78.9 \%$ cases, angulations in $31.6 \%$ and shortening in $10.5 \%$. In $68.4 \%$ cases, radiological union was seen within 20 weeks while $10.5 \%$ cases needed more than 30 weeks.

Ali et al. found that $25 \%$ cases had excellent, $45 \%$ had good, $30 \%$ had fair result based on bone score and $30 \%$ had excellent, $55 \%$ had good, $5 \%$ had fair and $10 \%$ had poor result based on functional score. The mean age of the study group was 25.5 years ${ }^{[4]}$.

Daragad et al. found that mean age of patients was 37.55 years. $95 \%$ patients were male and $5 \%$ were female. They noted $80 \%$ excellent, $15 \%$ good, $5 \%$ fair bone results and $85 \%$ excellent, $10 \%$ good, $5 \%$ poor functional results ${ }^{[2]}$.

Gudapati et al. reported that there were 23 males and 3 females with an average age of 32 years. The time required for lengthening varied from each category of case from 80 to 298 days. The most frequent complications were muscle contractures and joint stiffness in 5 cases, anterior bowing of femur in one case and intolerance to fixator in one case ${ }^{[12]}$. Magadum et al. found that the mean lengthening achieved 
was $10 \mathrm{~cm}$, mean union time 6.3 months, and mean duration of consolidation 10.2 months. Functional results were excellent in 19 patients and good in 5. The union time was longer in older patients ${ }^{[13]}$.

Wani and Syed found that all fractures united and infection eradicated completely. There were 13 excellent, nine good, and four fair results. Functional results were excellent in nine, good in 11, fair in five and poor in one. Pin site inflammation was the most common problem and occurred in $88 \%$ patients. There were no major complications or neurovascular complications ${ }^{[1]}$.

Results were assessed by Nesari et al. using bone score (ASAMI) and lower extremity functional scale. 68.4\% had excellent, $15.8 \%$ patients had good, $5.3 \%$ patients had fair, and $10.5 \%$ patients had poor result. $57.9 \%$ patients had minimal disability, $26.3 \%$ patients had moderate disability, $10.5 \%$ patients had severe disability, and 1 patient crippled ${ }^{[3]}$. It is seen that the results of the present study are similar to findings of other researchers. Differences in outcome may be associated with literacy of the patients and quality of selfcare.

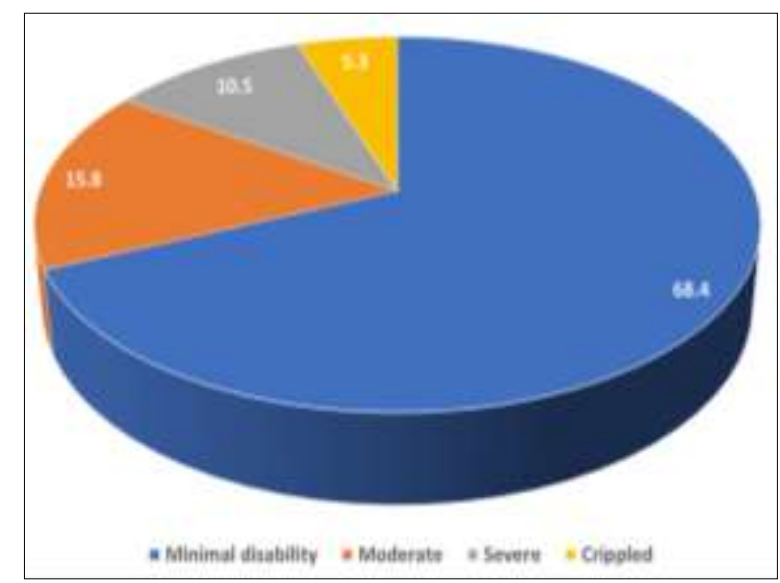

Chart 1: Showing functional outcome

\section{Conclusion}

Ilizarov fixator achieves stable fixation in cases with comminuted fractures and initial distraction increases soft tissue tension to help indirectly stabilize the fracture. It is recommended if there is extensive dissection and internal fixation is contraindicated. It was seen in the present study that $57.9 \%$ of the cases had excellent outcome and $26.3 \%$ showed good result. $68.4 \%$ had minimal disability while only $5.3 \%$ had severe disability. $68.4 \%$ cases showed radiological union within 20 weeks.

\section{References}

1. Wani NB, Syed B. Ilizarov ring fixator in the management of infected non-unions of tibia. SICOT-J 2015;1:22.

2. Daragad MS, Shettar CM. Ilizarov Treatment of Complex Non-Union Tibia. International Journal of Orthopaedics Traumatology \& Surgical Sciences 2016;2(2):286-92.

3. Nesari S, Wali P, Pasha M. Treatment of Tibial Fractures by Ilizarov Technique: A Longitudinal Study. IJSS Journal of Surgery 2015;1(6):6-9.

4. Ali S, Sujai S, Junied M, HC, HG, Swamy M. Evaluation of the functional outcome in open tibial fractures managed with an Ilizarov fixator as a primary and definitive treatment modality. Int $\mathbf{J}$ Orthop Sci 2017;3(2d):436-40.

5. Baruah R. Ilizarov methodology for infected non union of the Tibia: Classic circular transfixion wire assembly vs. hybrid assembly. Indian J Orthop 2007;41(3):198-203.

6. Jain S, Shah H, Shetty N, Patel M, Tekkati R, Khanna A. Study of efficacy of ilizarov external fixation in infected non union tibial fractures. Journal of Medical Thesis 2014;2(1):16-8.

7. Majumdar A, Chinnakali P, Vinayagamoorthy V, Daya PA, Shidam UG, Roy G. Opportunistic Screening for Hypertension and Selected Cardiovascular Risk Factors among Adults Attending a Primary Health Center in Puducherry, India. Int J Prev Med 2014;5(12):1616-20.

8. Sakale H, Agrawal AC, Kar B. Management of infected nonunion of tibia by Ilizarov technique. Journal of Orthopedics, Traumatology and Rehabilitation 2018;10(1):1-6.

9. Samanta AK, Ghosh S, Chaudhuri A, Mondal SC. Ilizarov ring fixator in treatment of infected nonunion of tibia. Saudi Journal of Sports Medicine 2016;16(2):15961.

10. Singh A, Ghosh S, Chaudhuri A, Datta S, Chowdhury A, Roy DS. Ilizarov fixator in management of nonunited and infected tibial shaft fractures. Medical Journal of Dr DY Patil University 2015;8(1):35-40.

11. Sreeram PRS. A study on functional outcome of ilizarov fixation in the management of infected non-union of long bones. Indian Journal of Orthopaedics Surgery 2016;2(2):187-93.

12. Gudapati O, Reddy AV. Ilizarov Ring External Fixator: An Experience. International Journal of Contemporary Medical Research 2017;4(6):1418-22.

13. Magadum M, Yadav CB, Phaneesha M, Ramesh L. Acute Compression and Lengthening by the Ilizarov Technique for Infected Nonunion of the Tibia with Large Bone Defects. J Orthop Surg (Hong Kong) 2006;14(3):273-9. 